\title{
EVOLUCIÓN DE POLÍTICAS MIGRATORIAS EN COLOMBIA FRENTE A LA DIÁSPORA VENEZOLANA $^{1}$
}

\section{Evolution of Migration policy in Colombia facing the Venezuelan diaspora}

María José Ruiz del Río ${ }^{2}$

María Carolina Hoyos Bula ${ }^{3}$

Recibido: 22 de abril de 2020 - Aceptado: 28 de mayo de 2020

\section{RESUMEN}

El presente artículo tiene como objetivo dilucidar y reflexionar sobre los conceptos más importantes alrededor de la migración de venezolanos, así como los desarrollos jurisprudenciales de la política migratoria en Colombia que han sido el resultado de las necesidades de los migrantes en la última década.

Palabras clave: Migración; migrantes venezolanos; refugiados; políticas públicas; derechos humanos.

\begin{abstract}
The objective of this article is to elucidate and reflect on the most important concepts around the migration of Venezuelans, as well as the jurisprudential developments of migration policy in Colombia that have been the result of the needs of migrants in the last decade.
\end{abstract}

Keywords: Migration; Venezuelan migrants; refugees; public policy; human rights.

\section{INTRODUCCIÓN}

La migración, a través de la historia ha sido un fenómeno inherente a la raza humana; desde el descubrimiento de América, y hasta en tiempos de guerra, se ha evidenciado el desplazamiento de los individuos que han tenido que trasladarse de un lugar a otro, voluntaria o involuntariamente, en búsqueda de oportunidades que les permitan tener una mejor calidad de vida.

\footnotetext{
1 El presente artículo de reflexión surge de la investigación denominada "Evolución de políticas migratorias en Colombia frente a la diáspora venezolana". Las autoras actuaron en calidad de investigadores principales y fue financiado por recursos propios dentro del Semillero de Investigación Ciencia y Proceso de la Facultad de Derecho de la Universidad de Cartagena, que está adscrito al grupo de investigación Filosofía del derecho, derecho internacional y problemas jurídicos contemporáneos de la misma Facultad.

2 Judicante en el Consulado de Colombia en Washington D.C. Orcid: https://orcid.org/0000-0001-5833-1599 E-mail: majoseruiz96@hotmail.com

3 Investigadora del Semillero de Investigación "Ciencia y Proceso" de la Universidad de Cartagena. Orcid https://orcid.org/0000-0001-9518-3935 E-mail: mariacarolinahoyosb@gmail.com
} 
En la actualidad, el flujo de migrantes aumenta cada día en todo el mundo, debido a que cada vez más personas desean residir de manera permanente o transitoria en un país distinto al de nacimiento o ciudadanía, ya sea por fines laborales, académicos, económicos, familiares, conveniencia personal, o por necesidad, entre otros.

Por otra parte, existen algunos grupos que se ven obligados a huir de su país de origen por conflicto o persecución, buscando así protección en otro Estado, como lo es el caso de los refugiados. Este, es un grupo específicamente definido y protegido por el derecho internacional; por lo que no debe entenderse como una subcategoría de los migrantes.

Mientras que la generalidad de los migrantes se desplaza en busca de un mejor futuro, los refugiados tienen que hacerlo para salvar su vida o su libertad. Migrantes y refugiados son tratados de distinta forma bajo las leyes internacionales, por lo que, cuentan con diferentes tipos de protección a sus derechos.

En Colombia, durante los últimos años se han empezado a construir políticas migratorias destinadas a proteger ambos grupos (migrantes y refugiados), con la finalidad de brindarles garantías y protección de derechos fundamentales, aunque tradicionalmente han sido los colombianos quienes han emigrado a otros Estados en busca de mejores futuros.

Por tal razón y teniendo en cuenta la ola de migrantes que ha enfrentado el país ha surgido solo hace una década, podríamos cuestionarnos ¿Cómo Colombia preparada para vivir la inmigración?

\section{Diáspora venezolana en Colombia}

En Colombia, los estudios sobre dinámicas migratorias han concluido que el inicio de la gran ola migratoria de venezolanos que ha arribado al país empezó en 2010, y ha incrementado desde el año 2011.

La Constitución Política de 1991 en su artículo 100, consagra que:

"Los extranjeros disfrutarán en Colombia de los mismos derechos civiles que se conceden a los colombianos. No obstante, la ley podrá, por razones de orden público, subordinar a condiciones especiales o negar el ejercicio de determinados derechos civiles a los extranjeros. Así mismo, los extranjeros gozarán, en el territorio de la República, de las garantías concedidas a los nacionales, salvo las limitaciones que establezcan la Constitución o la ley. Los derechos políticos se reservan a los nacionales, pero la ley podrá conceder a los extranjeros residentes en Colombia el derecho al voto en las elecciones y consultas populares de carácter municipal o distrital.” (Constitución Política de Colombia, 1991).

Esta norma reconoce a los inmigrantes en Colombia como sujetos de derecho, por lo que gozan de garantías y adquieren obligaciones.

Por su parte, la honorable Corte Constitucional, en sentencia SU - 677 de 2017 reiteró las reglas jurisprudenciales estudiadas en la materia y señaló lo siguiente: 
María José Ruiz del Río y María Carolina Hoyos Bula

“ (i) el deber del Estado colombiano de garantizar algunos derechos fundamentales de los extranjeros con permanencia irregular en el territorio es limitado; pues deben ser tratados en condiciones de igualdad respecto de los nacionales colombianos dentro de ciertos limites de razonabilidad que permiten tratos diferenciados; (ii) todos los extranjeros tienen la obligación de cumplir la Constitución Política y las leyes establecidas para todos los residentes en Colombia; y (iii) los extranjeros con permanencia irregular en el territorio nacional tienen derecho a recibir atención básica de urgencias con cargo al régimen subsidiado cuando carezcan de recursos económicos, en virtud de la protección de sus derechos a la vida digna y a la integridad física". (Corte Constitucional, 2017)

Ahora, haciendo énfasis en la situación actual que vive Colombia con la migración de venezolanos, se evidencia cada vez más que los conceptos, migrantes y refugiados, se encuentran inmersos en esta realidad del territorio colombiano y sus políticas migratorias. Sabemos que la principal causa de emigración venezolana es por falta de alimentos, medicinas y servicios esenciales, asimismo por violencia o inseguridad. Por otro lado, están también aquellos que salen de ese país por motivos de persecución, debido a que su vida o libertad se encuentran en peligro.

Colombia, anteriormente, había tenido un mayor flujo de emigración que de inmigración; sin embargo, en la última década el país ha tenido que enfrentarse a una gran ola migratoria de venezolanos que han cruzado la frontera, lo que ha obligado a que la política migratoria en el país inicie un proceso de evolución y adopte medidas que permitan su vigilancia y control migratorio.

Es por esto, la importancia de conocer y diferenciar correctamente los conceptos básicos de migrantes y refugiados en el marco del derecho internacional, migración y asilo, con el fin de garantizar la protección de los derechos de estas personas.

\section{Política Migratoria en Colombia}

En el derecho internacional sobre migración, se conoce como migrantes y refugiados, a una parte de las personas pertenecientes a este fenómeno. Los migrantes, son definidos como "toda persona que se traslada fuera de su lugar de residencia habitual, ya sea dentro de un país o a través de una frontera internacional, de manera temporal o permanente, y por diversas razones." (International Organization for Migration, 2019).

Por lo tanto, estos salen para mejorar sus vidas, dentro o fuera de su país.

Mientras que, los refugiados, son "personas que huyen del conflicto y la persecución. Su condición y su protección están definidas por el derecho internacional, y no deben ser expulsadas o retornadas a situaciones en las que sus vidas y sus libertades corran riesgo." (ACNUR, 2018)

En las migraciones internacionales, de las cuales hacen parte migrantes y refugiados; los individuos salen de su país a un país extranjero, donde su situación migratoria juega un papel fundamental en la estadía de estos individuos en el país que los recibe. 
Se entiende entonces por regularidad migratoria, la situación de quien ingresa al territorio de un país que no es el de su nacionalidad, cumpliendo los requisitos de las leyes migratorias de ese país, y por irregularidad migratoria; quien no cumpla con esos requisitos, por lo cual puede ser deportado en cualquier momento como un acto de sanción de una decisión tomada por el Estado.

Colombia ha tenido un carente desarrollo en materia de derechos migratorios a lo largo de la historia, por lo cual apenas hasta hace poco se empezó a considerar la existencia en el país una política migratoria que intenta satisfacer las necesidades sociales que se presentan desde la última década.

En los últimos años se han ido reglamentando aspectos de la migración, nuevos tipos de visas, procesos de regularización, entre otros; lo cierto es que, hasta el momento, existe una variedad de normas que han surgido debido a las necesidades reales de las poblaciones y todas ellas han sido sobre la marcha, pero, aun así, son normas dispersas que no alcanzan, hasta el momento, a lograr una integralidad o conexión clara entre ellas para constituir una política migratoria.

Si bien, solo a partir del año 2002, se incluyó por primera vez en Colombia dentro de un Plan Nacional de Desarrollo o PND (Ley 812, 2003), muy someramente, aspectos de la política exterior del país, pero fue hasta el siguiente PND (Ley 1151, 2007) que se convirtió este tema en uno de los ejes de acción.

María Teresa Palacios consideró que, se plantea el fortalecimiento de los nexos de los colombianos en el exterior, a partir de la creación y consolidación del programa "Colombia nos une". Asimismo, entre los principales avances en esta materia, se da creación a la tarjeta de registro consular, se busca la canalización de las remesas a través de las ferias inmobiliarias, se promueve un plan de homologación de títulos, entre otros aspectos. (Palacios, 2012, p.p. 89)

Por otra parte, el 24 de agosto de 2009 el Consejo Nacional de Política Económica y Social de Colombia intentó formular un planteamiento global de la migración con la propuesta de estructurar un plan integral de migración, con el fin de brindar atención tanto a los colombianos en el exterior como a los extranjeros en el país, pero su enfoque principal fue el de colombianos en el exterior, dejando de lado una vez más el tratamiento y la protección de los derechos de los extranjeros en Colombia.

Es entonces hasta la construcción del PND del periodo 2011 - 2014 (Ley 1450, 2011) que se tiene en cuenta la necesidad real de una política migratoria verdaderamente integral y enfocada en la protección de los derechos humanos tanto de los colombianos en el exterior como de los extranjeros en Colombia, por ello se considera que gracias a este PND surge la Ley 1465 (2011); por la cual se crea el Sistema Nacional de Migraciones (SNM).

La creación de este Sistema Nacional de Migraciones, en la norma, contempla una serie de principios enfocados a la protección de los derechos humanos, políticas de igualdad, 
María José Ruiz del Río y María Carolina Hoyos Bula

tolerancia y no discriminación, garantías democráticas, promoción de dialogo con los países de origen, tránsito y destino migratorio para el desarrollo de acuerdos, fortalecimiento institucional, entre otros; que, en resumen acompañarían al Gobierno Nacional en el diseño y ejecución de políticas públicas, planes y variedad de acciones encaminada a fortalecer los vínculos del Estado con los colombianos en el exterior y lograr una verdadera integralidad y concordancia de las políticas migratorias en el país.

En el mismo año, con el Decreto 4062; se crea la Unidad Administrativa Especial Migración Colombia, adscrita al Ministerio de Relaciones Exteriores; Migración Colombia fue creado para ejercer funciones de autoridad, vigilancia y control migratorio y de extranjería en el país, de nacionales y extranjeros en Colombia, ejercer funciones de Policía Judicial en coordinación con la Fiscalía General de la Nación, expedir documentos relacionados con cedulas de extranjería, salvoconductos, prorrogas de permanencia, permiso de ingreso, registro de extranjeros, entre otros trámites.

\section{Visado en Colombia}

El Ministerio de Relaciones Exteriores, siendo el encargado de la política exterior del país, las relaciones internacionales y la administración exterior de la República, mediante Resolución 6045 del 2 de agosto de 2017, establece tres tipos de visa: Visa de Visitante o Visa tipo V, Visa de Migrante o Visa tipo M y Visa de Residente o Visa tipo R.

- La Visa tipo V, se otorga al extranjero que desee entrar y salir del país o que desee permanecer en el territorio sin establecerse, para desarrollar alguna de las actividades mencionadas en el capítulo 1, artículo 10 de la resolución.

- La Visa M, tiene una vigencia máxima de 3 años, es para el extranjero que desee permanecer en Colombia con la intención de establecerse y no cumpla con las condiciones de la visa $\mathrm{R}$. Las condiciones para solicitar la visa $\mathrm{M}$ se encuentran estipuladas en el capítulo 2, articulo 17 de la resolución en mención.

- La Visa R, tiene vigencia indefinida, y es para el extranjero que desee establecerse permanentemente o domiciliarse en el país. Debe satisfacer alguna de las condiciones para la visa tipo $\mathrm{R}$, establecidas en el capítulo 3, articulo 21 de la resolución.

En la misma línea del visado, dentro de la documentación que autoriza la permanencia en el territorio colombiano, la Unidad Administrativa Especial Migración Colombia, mediante Decreto 4000 de 2004, articulo 77 y regulado mediante Directiva 11 de 2012, establece la cédula de extranjería como documento de identidad que se otorga a extranjeros mayores de 18 años y titulares de una visa con una vigencia superior a 3 meses.

Las visas que otorga Colombia permiten legalizar el ingreso y estancia de extranjeros en el país. Por tanto, estos pueden gozar de los mismos derechos civiles que se concede a los nacionales colombianos, a excepción de aquellos derechos que la ley subordine a condiciones especiales o niegue a los extranjeros, en cuanto a los derechos políticos, aunque se reservan a los colombianos, el Estado le concede el derecho al voto a las elecciones y a las consultas populares de carácter distrital y municipal al extranjero residente en Colombia. 
Teniendo en cuenta la importancia de las visas para el ingreso y estancia de los extranjeros en el territorio colombiano, cabe resaltar que, existen circunstancias en las cuales un extranjero no requiere de visado para el ingreso al país, ya sea dado a su nacionalidad o la actividad que realizará en el territorio.

Mediante Resolución 1220 de 2016, Migración Colombia, establece como autorización para la permanencia en el territorio colombiano, el Permiso de Ingreso y Permanencia (PIP), el cual se otorga a "extranjeros que pretendan ingresar al territorio nacional, sin vocación de domicilio y permanencia y que no requieran visa; con motivación en las actividades manifestadas y en cumplimiento de los requisitos migratorios específicos." (Migración Colombia, 2016).

Al igual que un extranjero que ingresa al país con visa, estos disfrutan de los mismos derechos civiles que los colombianos, a excepción de aquellos derechos que la ley subordine a condiciones especiales o niegue a los extranjeros, puesto que, al no requerir visa, se les otorga el Permiso de Ingreso y Permanencia, el cual autoriza su estadía en el territorio.

Por otro lado, en el caso especial de los venezolanos, la política migratoria en Colombia mediante la Unidad Administrativa Especial Migración Colombia, ha implementado medidas de flexibilización migratoria para el acceso a los derechos de los migrantes venezolanos en el país, entendiendo que la crisis económica de Venezuela ha generado un flujo abundante de esta población en el territorio colombiano.

Por ello, mediante Resolución 5797 del 25 de julio de 2017, se creó el Permiso Especial de Permanencia (PEP), otorgado a los nacionales venezolanos que se encuentren en el territorio nacional sin la intención de establecerse. Esto les permite ejercer cualquier actividad u ocupación legal en Colombia, incluyendo las emanadas de un vínculo laboral, en un tiempo de 90 días prorrogables automáticamente hasta dos años. Por lo que, una vez finalice la vigencia de esta documentación, el individuo debe abandonar el país o incurrirá en permanencia irregular, enlodando así su récord migratorio, dificultando más adelante un nuevo ingreso al territorio colombiano.

Con el Permiso Especial de Permanencia, los venezolanos adquieren derechos civiles como cualquier extranjero, además, tienen derecho al trabajo, en respuesta a la crisis humanitaria que afrontan los ciudadanos venezolanos que deciden migrar al territorio colombiano en busca de oportunidades laborales y un sustento económico. También, acceso a educación, salud y libre tránsito al interior del territorio.

Como otra de las medidas de flexibilización migratoria para el acceso a los derechos de los migrantes venezolanos en el país, Migración Colombia creó la Tarjeta de Movilidad Fronteriza (TMF), documento que permite a los nacionales venezolanos el ingreso, tránsito y salida del territorio colombiano en zona de frontera por una vigencia de dos años.

Con este documento, el nacional venezolano puede permanecer en las zonas delimitadas de frontera por siete días continuos con el fin de realizar actividades no remuneradas o de 
María José Ruiz del Río y María Carolina Hoyos Bula

tránsito, suplir necesidades básicas como abastecerse de alimentos, medicinas, productos de higiene personal, entre otros, escasos en su país; la concesión de este documento, permite el acceso a derechos inalienables al ser humano como la subsistencia como necesidad básica. También, el derecho a que se establezca un orden social e internacional en el que los derechos y libertades se hagan plenamente efectivos.

Estas medidas de flexibilización migratoria que se han implementado para los migrantes venezolanos, permiten no solo que este ingrese al territorio colombiano con la autorización pertinente como Estado receptor, si no que sea protegido por todas las prerrogativas constitucionales de Colombia.

\section{Reconocimiento de la condición de Refugiado en Colombia}

Teniendo en cuenta que los refugiados hacen parte de las personas pertenecientes al fenómeno de la migración, es importarte resaltar que este grupo, esta específicamente definido y protegido por el Derecho Internacional en la Declaración de los Derechos Humanos (ONU: 1948) y en la Convención 1951 sobre el Estatuto de los Refugiados. (ONU: 1951).

La Convención 1951 sobre el Estatuto de los Refugiados, proporciona un mandato para la comunidad internacional de asistir a las personas en necesidad de protección y la aplicación del principio de no devolución y el acceso al territorio; el cual prohíbe que un refugiado sea expulsado o regresado a la situación donde su vida o libertad estaba en peligro.

Los Estados firmantes deben establecer procedimientos para las peticiones de asilo y estar dispuestos a admitir a aquellos que califican como refugiados.

Colombia es Estado Parte de la Convención, ratificada el 10 de octubre de 1961 y del Protocolo sobre el Estatuto de Refugiados, al cual adhirió Colombia el 4 de marzo de 1980. Por lo que, este Estado aplica el término de refugiado de la Convención, el cual establece que refugiado es toda persona que:

“debido a fundados temores de ser perseguida por motivos de:

1. Raza

2. Religión

3. Nacionalidad,

4. Pertenencia a determinado grupo social

5. Opiniones políticas,

Se encuentre fuera del país de su nacionalidad y no pueda o, a causa de dichos temores, no quiera acogerse a la protección de tal país; o que, careciendo de nacionalidad y hallándose, a consecuencia de tales acontecimientos, fuera del país donde antes tuviera su residencia habitual, no pueda o, a causa de dichos temores, no quiera regresar a él” (Convención sobre el Estatuto de Refugiados, 1951)

En Colombia, el derecho de asilo es reconocido en el artículo 36 constitucional en los términos previstos en la ley, y su procedimiento es regulado por el Decreto 1067 de 2015 ; 
el cual indica que la solicitud para el reconocimiento de la condición de refugiado en Colombia deberá presentarse ante el Ministerio de Relaciones Exteriores. Si bien, toda persona tiene derecho a solicitar asilo en otro Estado, es el Estado receptor quien de acuerdo a la normatividad existente determinará su condición de refugiado, o no.

A través de la Comisión Asesora para la Determinación de la Condición de Refugiado se reciben, tramitan y estudian las solicitudes presentadas por quienes consideran que se ajustan a esta definición.

Según el Artículo 2.2.3.1.1.1. del Decreto 1067 (2015), refugiado es toda persona:

“a) Que debido a fundados temores de ser perseguida por motivos de raza, religión, na-cionalidad, pertenencia a determinado grupo social u opiniones políticas, se encuentre fuera del país de su nacionalidad y no pueda o, a causa de dichos temores, no quiera acogerse a la protección de tal país; o que, careciendo de nacionalidad y hallándose, a consecuencia de tales acontecimientos, fuera del país donde antes tuviera su residencia habitual, no pueda o, a causa de dichos temores, no quiera regresar a él;

b) Que se hubiera visto obligada a salir de su país porque su vida, seguridad o libertad han sido amenazadas por violencia generalizada, agresión extranjera, conflictos internos, violación masiva de los derechos humanos $u$ otras circunstancias que hayan perturbado gravemente al orden público.

c) Que haya razones fundadas para creer que estaría en peligro de ser sometida a tortura u otros tratos o penas crueles, inhumanos o degradantes en caso de que se procediera a la expulsión, devolución o extradición al país de su nacionalidad o, en el caso que carezca de nacionalidad, al país de residencia habitual."

Las personas que solicitan la condición de refugiado, deben tener, específicamente, un temor fundado de persecución en razón de, por lo menos, uno de los cinco motivos mencionados en la Convención 1951 y acogidos mediante el Decreto 1067 de 2015, con el fin de que el Estado Colombiano pueda otorgarles dicha condición.

Mientras el individuo se encuentra a la espera de la resolución de su procedimiento de asilo se le conoce como solicitante de asilo, por lo que aún no posee la condición de refugiado, mientras se encuentran en el país en estas condiciones, Migración Colombia expide un salvoconducto de permanencia mientras reciben una respuesta a la solicitud, el cual solo les otorga derecho a la salud; es decir, mientras se encuentre en esta espera indefinida el solicitante no tiene permitido trabajar en Colombia o abrir una cuenta de banco, pues para ello es estrictamente necesario tener un documento de regularización.

Una vez sea reconocido como refugiado por el país, este le brinda protección internacional y se aplica el principio de no devolución. Cabe aclarar que la condición de refugiado se otorga solo a civiles y solo podrá ser otorgada a soldados que hayan dejado las armas.

Quien posee la condición de refugiado en Colombia, se le concede la visa $\mathrm{M}$, dado que el reconocimiento de la condición de refugiado, entra bajo ese parámetro. Por ende, se le 
María José Ruiz del Río y María Carolina Hoyos Bula

otorgan los mismos derechos civiles básicos y la misma ayuda que a cualquier extranjero que sea residente. Así como también, los derechos económicos y sociales fundamentales. A su vez, a quien se le sea concedida la condición de refugiado, debe respetar las leyes y reglamento del país.

\section{Protección a migrantes y refugiados venezolanos en Colombia.}

En cuando a la protección de derechos de migrantes y refugiados venezolanos en Colombia, estos han podido acceder a amparos que ha logrado establecer el Estado colombiano con el desarrollo de sus políticas migratorias, con la finalidad de garantizar los derechos fundamentales de estos grupos.

El migrante venezolano en Colombia tiene de primera mano acceso al permiso especial de permanencia, el cual le otorga derechos civiles, derecho al trabajo, a la educación, a la salud y al libre tránsito al interior del territorio, cuentan también con la tarjeta de movilidad fronteriza, la cual otorga el acceso a derechos inalienables al ser humano como la subsistencia, satisfacción de necesidades básica y el derecho a que se establezca un orden social e internacional en el que los derechos y libertades se hagan plenamente efectivos.

En cuanto a los derechos de salud y la satisfacción de necesidades básicas, la jurisprudencia ha sostenido en la sentencia T - 025 de 2019 que:

"Es necesario precisar las reglas por las cuales el servicio de salud a los extranjeros no residentes no puede negarse, por cuanto se hace necesario atender sus necesidades básicas y hacer prevalecer su vida, lo cual comporta el derecho a recibir por lo menos un mínimo de servicios de atención de urgencias cuando: i) no haya un medio alternativo, ii) la persona no cuente con recursos para costearlo y iii) se trate de un caso grave y excepcional. Ello no exime a los extranjeros de la obligación que tienen de adquirir un seguro médico o un plan voluntario de salud, tal y como se encuentra previsto en el parágrafo $1^{o}$ del artículo 32 de la Ley 1438 de 2011, una vez sea conjurada la situación de urgencia y, además, cumplir con los requisitos para la afiliación al Sistema, a fin de obtener un servicio integral y previo a ello aclarar el estatus migratorio." (Corte Constitucional, 2019)

Por otra parte, una vez se ha reconocido la condición de refugiado, se le garantiza al extranjero sus derechos fundamentales, brindando la protección internacional y aplicando el principio de no devolución como norma obligatoria.

La importancia de entender y diferenciar estas dos figuras (migrante y refugiado), radica en el periodo de protección puede brindar el Estado receptor, pues, a pesar de adquirir derechos similares; el refugiado venezolano puede permanecer en el territorio colombiano por un periodo de tiempo más amplio del que otorga la vigencia de la Visa M, la cual adquiere con esa condición, esto le permite aplicar para residencia en Colombia con la Visa $\mathrm{R}$, una vez cumplidos dos años ininterrumpidos en el territorio colombiano por tiempo de residencia acumulado. 
Mientras que, la estancia o tránsito del migrante venezolano que accede con la documentación expedida como medida de flexibilización migratoria en el país, no supera un periodo de dos años. Por lo cual, deberá abandonar el territorio colombiano al no contar con alguna de las documentaciones que le permite su estancia, y con ello la pérdida de derechos que se les había otorgado con dicha documentación.

Por otra parte, tenemos el Permiso Especial de Permanencia (PEP), que, dada su naturaleza jurídica, está dirigido a autorizar la permanencia de los nacionales venezolanos que se encuentren en el territorio nacional sin la intención de establecerse, razón por la cual, no equivale a una Visa, ni tiene efectos en el cómputo de tiempo para la Visa de Residencia Tipo "R". Sin embargo, una vez terminado este periodo, como cualquier otro extranjero, puede optar por otras opciones de visa, pero para ello debe cumplir ciertos requisitos, que le permitan solicitar alguna de ellas.

\section{CONCLUSIÓN}

Esta diáspora venezolana de los últimos años que indiscutiblemente ha tenido impacto directo en el Estado Colombiano y el desarrollo de sus políticas migratorias, pone en evidencia que el país se encuentra a medio camino, aún quedan medidas y procesos por mejorar o implementar para garantizar de forma efectiva la protección de derechos de los migrantes y refugiados que ingresan al territorio nacional, como si podría hacerlo un sistema de migraciones verdaderamente integral y basado en la protección de los derechos humanos, que sería el "deber ser".

Es innegable que, en Colombia, las instituciones públicas y privadas, e incluso partes de la sociedad aún no se adaptan ni conocen todos los alcances y derechos que otorgan a los venezolanos estos documentos de regularización no convencionales en la política migratoria, fomentándose así la xenofobia y la vulneración de derechos de estos grupos. Existen incluso casos de instituciones, especialmente del área de la salud y la educación, que se rehúsan a prestar sus servicios a los individuos que se identifican con dicha documentación, por lo que, le están negando derechos a salud y educación a los migrantes venezolanos a causa del desconocimiento de los procedimientos y el desarrollo que ha tenido la política migratoria en el país.

Es por esto la importancia y necesidad de capacitación urgente para las instituciones y entidades prestadoras de servicios en cuanto a estas políticas, así como procurar una mejor educación social a los colombianos con respecto a los migrantes venezolanos, con el fin de obtener un fortalecimiento eficaz de las políticas migratorias colombianas, brindar verdadera protección y garantía de derechos a los migrantes y concientizar a la sociedad para que también vele porque las normas se cumplan.

Finalmente, en cuanto a la condición de refugiado, para el año 2019, según informes de cancillería, se habían presentado en Colombia alrededor de 10.479 solicitudes de reconocimiento de refugiado radicadas por la población venezolana y solo resuelto un poco más de 145 solicitudes a la fecha. Esto pone de presente la necesidad de replantear el sistema de reconocimiento de refugiados para lograr descongestionarlo y proferir una 
María José Ruiz del Río y María Carolina Hoyos Bula

decisión de fondo y oportuna a estas solicitudes, sin necesidad de tener una espera indefinida que cree una barrera de irregularidad migratoria para los solicitantes de asilo.

Teniendo en cuenta el flujo de solicitudes de reconocimiento de refugiados de venezolanos en el país, y tomando como referencia el reconocimiento masivo de venezolanos que tuvo Brasil a finales de 2019, identificando en ellos un perfil similar, se hace necesario plantear la posibilidad de evaluar en Colombia un reconocimiento de refugiados grupal, denominado como refugiados prima facie; esto soportado en que Venezuela ya ha sido reconocida como una población que necesita protección internacional, lo que permitiría este reconocimiento grupal.

\section{REFERENCIAS BIBLIOGRÁFICAS}

Agencia de la ONU para los Refugiados (1951) Convención 1951 sobre el Estatuto de los Refugiados. Nueva York: ONU. Recuperado de https://www.acnur.org/la-convencionde1951.html\#: :text=La\%20Convenci\%C3\%B3n\%20sobre\%20el\%20Estatuto,los\%20 Estados\%20para\%20su\%20protecci\%C3\%B3n.

Agencia de la ONU para los Refugiados. (2018) Solicitantes de asilo. Nueva York: ONU. Recuperado de https://www.acnur.org/solicitantes-de-asilo.html

Agencia de la ONU para los Refugiados. (2018) Refugiados. Nueva York: ONU. Recuperado de https://www.acnur.org/refugiados.html

Cancillería de Colombia. (s.f.) Reconocimiento de la condición de refugiado. Bogotá, Colombia: Ministerio de Relaciones Exteriores. Recuperado de https://www.cancilleria.gov.co/international/politics/refugee

Consejo Nacional de Política Económica y Social (2009). Documento Conpes 3603 de 2004: Política Integral Migratoria. Bogotá, Colombia: Departamento Nacional de Planeación. Recuperado https://colaboracion.dnp.gov.co/CDT/Conpes/Econ\%C3\%B3micos/3603.pdf

Constitución Política de Colombia. Artículo 100, 7 de julio de 1991 (Colombia).

Corte Constitucional. Sentencia SU - 677 de 2017. (M.P. Gloria Stella Ortiz Delgado). 15 de noviembre de 2017.

Corte Constitucional. Sentencia T - 025 de 2019. (M.P. Alberto Rojas Ríos). 29 de enero de 2019.

De León Vargas, G. (2018). Diáspora venezolana, Cartagena más allá de las cifras. Revista Jurídica Mario Alario D'Filippo, Vol 10, número 20: 111-119. DOI: https://doi.org/10.32997/2256-2796-vol.10-num.20-2018-2150 
Decreto 4000 de 2004. Con fuerza de ley. Por el cual se dictan disposiciones sobre la expedición de visas, control de extranjeros y se dictan otras disposiciones en materia de migración. 30 de noviembre de 2004. D.O. 45749.

Decreto 1067 de 2015. Ministerio de Relaciones Exteriores. Por medio del cual se expide el Decreto Único Reglamentario del Sector Administrativo de Relaciones Exteriores. 26 de mayo de 2015. D.O. 49.523.

Decreto 4062 de 2011. Por el cual se crea la Unidad Administrativa Especial Migración Colombia, se establece su objetivo y estructura. 31 de octubre de 2011.

Directiva 11 de 2012. Alcaldía Mayor de Bogotá. Promoción y uso de software libre en el distrito capital. Noviembre de 2012.

Escobar-Espino, A. y Angulo-Pico, G. (2015). Panorama Económico in the context of the international visibility of scientific journals. Panorama Económico, Vol. 23: 11-13. DOI: https://doi.org/10.32997/2463-0470-vol.23-num.1-2015-1387

International Organization for Migration, (2019) Glossary on migration, No. 34. Nueva York: ONU. Recuperado de https://www.iom.int/es/terminos-fundamentales-sobremigracion

Kalach Torres, Gina María (2016). Las comisiones de la verdad en Colombia. Revista Jurídica Mario Alario D'Filippo, Vol 8, número 16: 106-124. DOI: https://doi.org/10.32997/2256-2796-vol.8-num.16-2016-1534

Ley 1465 de 2011. Por la cual se crea el Sistema Nacional de Migraciones y se expiden normas para la protección de los colombianos en el exterior. 29 de junio de 2011. D.O. 48.116 .

Ley $N^{\circ} 812$ Por la cual se aprueba el Plan Nacional de Desarrollo 2002-2006, Hacia un Estado Comunitario. Junio 26, 2003. DO 45.231

Ley $N^{\circ} 1151$ Por la cual se aprueba el Plan Nacional de Desarrollo 2006-2010 Estado Comunitario: desarrollo para todos. Julio 24, 2007. DO 46700

Ley $N^{\circ} 1450$ Por la cual se expide el Plan de Desarrollo 2011-2014.Prosperidad para todos. Junio 16, 2011. DO 48102

Luna Salas, F. (2019). Hechos, Verdad y Prueba. En F. Luna y E. de Río. Compendio de Derecho Probatorio Contemporáneo, p. 39-59. Bogotá, Colombia: Grupo Editorial Ibáñez.

Luna Salas, F. (2019). Técnicas neurocientíficas como medio de prueba pericial. Revista Prolegómenos, Vol. 22, Número 44: 143-154 DOI: https://doi.org/10.18359/prole.4160

Organización de Naciones Unidas/ONU, Asamblea General (1948) Declaración Universal de derechos Humanos. París: ONU 
María José Ruiz del Río y María Carolina Hoyos Bula

Palacios, M. (2012) El sistema colombiano de migraciones a la luz del derecho internacional de los derechos humanos: la Ley 1465 de 2011 y sus antecedentes normativos. Opinión Jurídica, Vol. 11, No. 21, p.p. 83-102.

Resolución 1220 de 2016. Unidad Administrativa Especial Migración Colombia. Por la cual se establecen los Permisos de Ingreso y Permanencia, Permisos Temporales de Permanencia, y se reglamenta el Transito Fronterizo en el territorio nacional. 12 de agosto de 2016.

Resolución 5797 de 2017. Ministerio de Relaciones Exteriores. Por medio del cual se crea un Permiso Especial de Permanencia. 25 de julio de 2017.

Resolución 6045 de 2017. Ministerio de Relaciones Exteriores. Por la cual se dictan disposiciones en materia de visas y deroga la Resolución 5512 del 4 de septiembre de 2015. 2 de agosto de 2017.

Sánchez, K. (3 de junio de 2020). "En esto del refugiado, uno se tiene que volver un completo estratega". VOA Noticias. Recuperado de https://www.voanoticias.com/america-latina/testimonios-refugiados-venezolanos-encolombia

Viguri Perea, A. y Chiara Marullo, M. (2016) El derecho a un medio ambiente sano y la encrucijada de los alimentos transgénicos. Revista Jurídica Mario Alario D'Filippo, Vol. 8, Número 15: 100-111. DOI: https://doi.org/10.32997/2256-2796-vol.8-num.15-2016$\underline{1526}$ 